\section{A MINIMAL COST FUNCTION METHOD \\ FOR OPTIMIZING THE AGE-DEPTH \\ RELATION OF DEEP-SEA SEDIMENT \\ CORES}

Wolfgang Brüggemann

Max-Planck-Institut für Meteorologie Hamburg Hamburg, Germany

Abstract. The question of an optimal agedepth relation for deep-sea sediment cores has been raised frequently. The data from such cores (e.g., $\delta^{18} \mathrm{O}$ values) are used to test the astronomical theory of ice ages as established by Milankovitch in 1938. In this work, we use a minimal cost function approach to find simultaneously an optimal age-depth relation and a linear model that optimally links solar insolation or other model input with global ice volume. Thus a general tool for the calibration of deep-sea cores to arbitrary tuning targets is presented. In this inverse modeling type approach, an objective function is minimized that penalizes: (1) the deviation of the data from the theoretical linear model (whose transfer function can be computed analytically for a given age-depth relation) and (2) the violation of a set of plausible assumptions about the model, the data and the obtained correction of a first guess age-depth function. These assumptions have been suggested before but are now quantified and incorporated explicitly into the objective function as penalty terms. We formulate

Copyright 1992

by the American Geophysical Union.

Paper number 92PA01235. 0883-8305/92/92PA-01235 \$10.00 an optimization problem that is solved numerically by conjugate gradient type methods. Using this direct approach, we obtain high coherences in the Milankovitch frequency bands (over $90 \%$ ). Not only the data time series but also the the derived correction to a first guess linear age-depth function (and therefore the sedimentation rate) itself contains significant energy in a broad frequency band around $100 \mathrm{kyr}$. The use of a sedimentation rate which varies continuously on ice age time scales results in a shift of energy from $100 \mathrm{kyr}$ in the original data spectrum to 41 , 23 , and $19 \mathrm{kyr}$ in the spectrum of the corrected data. However, a large proportion of the data variance remains unexplained, particularly in the $100 \mathrm{kyr}$ frequency band, where there is no significant input by orbital forcing. The presented method is applied to a real sediment core and to the SPECMAP stack, and results are compared with those obtained in earlier investigations.

\section{INTRODUCTION}

Proxy data from deep-sea cores have been used extensively to test the orbital theory of ice ages introduced by Milankovitch [1938]. A problem in the direct comparison between time-dependent forcing (changes in solar insolation) and space- 
(i.e., depth-) dependent data, however, is that there is no accurate experimental age-dating procedure for the long time intervals considered. Shackleton et al. [1990] suggested that even wellestablished ages (such as the Brunhes/Matuyama. boundary at $730 \mathrm{ka}$ ) might be underestimated by up to $7 \%$ (with a correct value $780 \mathrm{ka}$ ). Recently, this hypothesis has received independent support by Hilgen [1991] using a similar astronomical tuning approach and by Izett and Obradovich [1991] for the case of the Brunhes/Matuyama boundary (new estimate at $790 \mathrm{ka}$ ) and by Walter et al. [1991] for older isotopic events from a ${ }^{40} \mathrm{Ar} /{ }^{39} \mathrm{Ar}$ analysis using a single-crystal laserfusion technique.

Here we present a universal tool for testing orbital and other theories of ice ages. The method used produces optimal age-depth functions for arbitrary cores and is subjective only in terms of the choice and the relative importance of the different components of the objective function. In contrast to previous approaches, the user can quantify a priori some subjective preference for different features of the final solution (e.g., deviation from an initial first guess age-depth function), and thus explore the sensitivity of the final solution to the relative importance of the different criteria used.

This work pursues two simultaneous goals. First, we try to find an optimal response function for a linear system of arbitrary high order that links solar insolation with climate indices, for example, global ice volume as represented by the ratio of stable oxygen isotopes. The solar insolation varies with the geometry of the Earth's orbit around the Sun and can be computed numerically for at least the last million years [Berger, 1978]. In the frequency domain, this input contains significant energy only in the Milankovitch frequency bands of 41,23 , and $19 \mathrm{kyr}$. In further experiments, we use also the sum of the normalized orbital parameters (the so-called ETP time series) [cf. Imbrie et al., 1984] as system input which in addition contains energy in the 100 kyr frequency band.

Second, we are looking for an age-depth function for the data such that the difference between model output (as a function of time) and clata (as a function of depth in the core) is minimized in the least squares sense.

In order to achieve these two goals, we formulate an objective function for an optimization problem, where additional requirements for numerical stability and physical plausibility are incorporated into the objective function as penalty terms. This idea originally goes back to the work of Hasselmann and Herterich [1983], who suggested minimizing the weighted sum of the following five components: (1) the deviation between the model and the data, (2) the deviation of the optimal age-depth relation at well-dated points (e.g., the Brunhes/Matuyama boundary) from their ages determined by other means, (3) the overall deviation of the optimal age-depth relation from a first guess (which in a standard case is assumed to be a linear interpolation between the present and the Brunhes/Matuyama boundary at $730 \mathrm{ka}),(4)$ the square of the second derivative of the new age-depth relation, and (5) the overall deviation of the optimal linear model from a preferred linear model (which in the following is assumed to be of first order).

The choice of the different constants and fixed functions in these components (i.e., well-dated points, initial age-deptl function) is subjective and expresses the users individual preference about different age-depth functions. In this approach, however, the subjectivity is incorporated a priori into the objective function and an optimal solution is found with respect to these preferences.

Hasselmann and Herterich [1983] suggested that this optimization problem could be solved by an iterative process of integrating Euler's equations (the necessary condition for optimality of the correction of the initial age-depth function derived from variational calculus), computing the transfer function of the optimal linear model analytically, and optimizing with respect to the remaining parameters. In this paper we begin with a similar weighted objective function that includes an additional term to assure a monotonically increasing age-depth relation. However, this objective function is subsequently minimized directly by a conjugate-gradient type algorithm where derivatives are computed numerically.

The procedure for determining an optimal agedepth relation of deep-sea cores is tested by applying it to data of the Meteor core M 13519 [Sarnthein et al., 1984] and to the SPECMAP stack [Imbrie et al., 1984]. The results are compared with earlier studies by Herterich and Sarnthein [1981], Shackleton and Matthews [1977], Imbrie et al. [1984], and Herterich [1988]. 
A rather similar approach has recently been explored by Grieger [1992]. In his work a function $t(z)$ is introduced that maps points in the core to the corresponding ages; this is the reverse of the $z(t)$ mapping adopted here. Grieger's objective function and the model restrictions are formulated in the time domain rather than the frequency domain.

The most widely applied method for dating cores for the last 900 liyr is the approach used by Imbrie et al. [1984] to establish the SPECMAP age-depth relation. Following the initial work by Hays et al. [1976], the SPECMAP age-depth relation was obtained by passing the orbital parameters (obliquity and precession index) rather than the solar insolation through an exponentially damped system with a time constant of $17 \mathrm{kyr}$. The output curve obtained (ETP) was used as the target for the filtered data curves. The best fit was determined iteratively for the different frequency bancls by phase locking the clata to the orbital parameter curves and averaging over several cores.

Another inverse method was suggested by Martinson et al. [1982] in orcler to correlate two given time series, which are related to each other by a mapping function $x(t)$. This mapping function is assumed to be a linear trend modified by a trun- cated Fourier series. The trend parameter and the Fourier coefficients then form the independent vector for a coherence maximization problem. This is solved by an iterative steepest ascent method with additional constraints for a constant step length in order to prevent the system of the normal equations from becoming unstable prematurely. However, this method was applied to artificial clata sets, to two different deep-sea sediment cores, and to correlate two profiles from the Southeast Indian Ridge in order to determine the differential spreading rate but has not been used to investigate the case of orbital forcing. Thus the calibration by Martinson et al. [1982] establishes only a relative depth-clepth mapping function in contrast to the absolute depth-time relation obtained from astronomical time series in this study.

Martinson et al. [1987] provided a high-resolution chronostratigraphy for the last $300 \mathrm{kyr}$ by averaging the results of four clifferent orbital tuning approaches. Each of these approaches was based on different assumptions:

1. The "phase locked approach" assumes constant phase between dominant components of orbital forcing and the corresponding components in the geological clata.

2. The "direct response approach," where the response is assumed to mimic the forcing, consis-

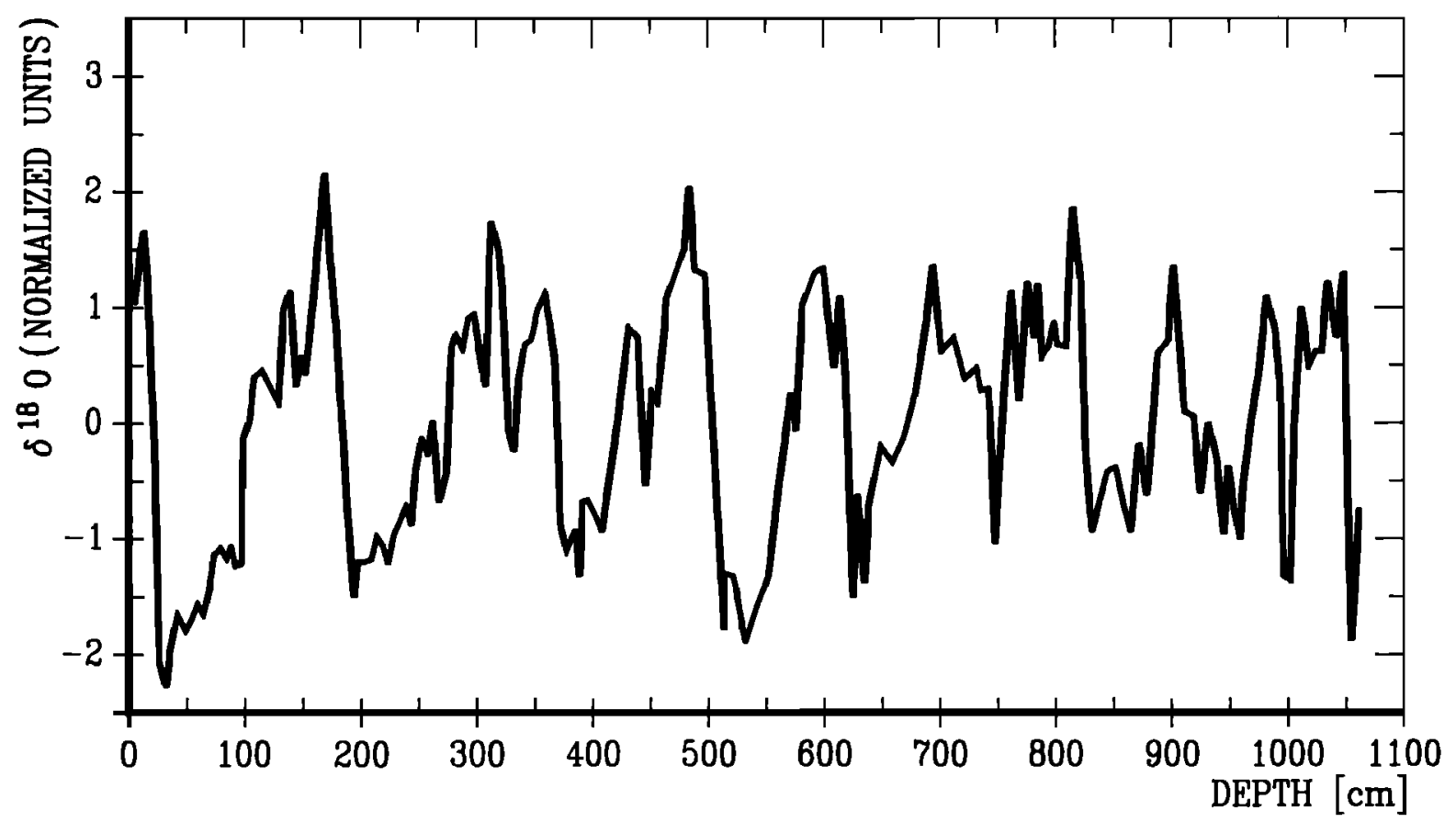

Fig. 1. $\delta^{18} \mathrm{O}$ data curve of Meteor core M 13519 [from Sarnthein et al., 1984]. 
tent with the original Milankovitch theory.

3. The "nonlinear response approach" uses the nonlinear model of Imbrie and Imbrie [1980] consisting of two simple linear models with different time constants for warming and cooling.

4. The "pure components approach" is comparable to the original idea of Hays et al. [1976], further developed by Imbrie et al. [1984] mentioned above. Here the tuning target is constructed from the linear combination of "pure" (i.e., orbital rather than solar insolation) components and their harmonics.

The final chronology was determined to have an average error of $5 \mathrm{kyr}$. This error analysis is based on averaging over different tuning approaches which are all assumed to be equally plausible.

Shackleton and Matthews [1977] derived a depth-time relation by directly correlating coral terraces in Barbados with the oxygen isotope stratigraphic record. Herterich and Sarnthein [1984] tested three different approaches using data from Meteor core M 13519. They obtained the injtial age-depth function "LIN" by linear interpolation between radiometrically dated points. The "CARPOR" age-depth relation is also based on radiometric data and was developed under the twin assumptions of constant accumulation rate of aeolian dust near the thermal equator and the influence of differential porosity and calciumcarbonate dissolution on the short-term sedimentation rates. Two further age-depth relations were again obtained by orbital tuning ("TUNE" and "STUNE"). The second approach differs from the first by keeping the isotopic stage boundary

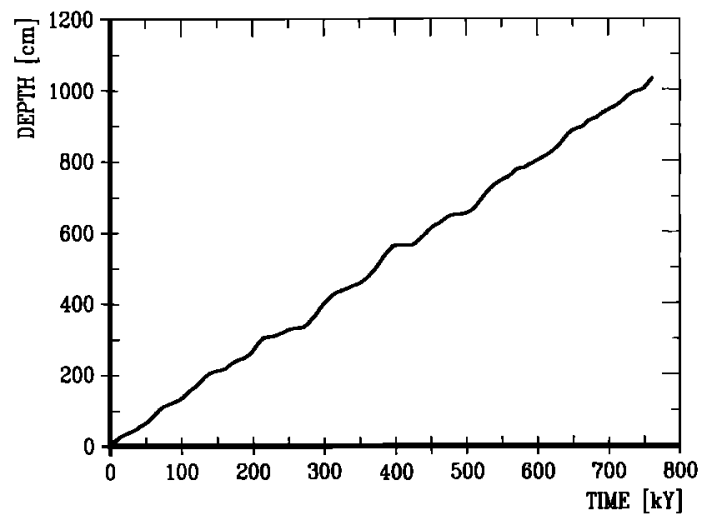

Fig. 2. The standard run optimal age-depth function for Meteor core M 13519.
5/6 [cf. Sarnthein et al., 1984; Prell et al., 1986] and the Brunhes/Matuyama magnetic reversal fixed at 127 and $730 \mathrm{ka}$, respectively. The goal of both approaches was to maximize squared coherence, which reaches values of up to $75 \%$.

Herterich [1988] considered an objective function similar to that originally developed by Hasselmann and Herterich [1983]. The optimal model (of arbitrary high order) and the preferred model were assumed to be identical, and an age-depth relation was found for the last $300 \mathrm{kyr}$. The solution was obtained by an iterative process of integrating Euler's equation for the age-clepth function and optimizing the objective function with respect to the remaining model parameters.

Recently, Shackleton et al. [1990] suggested that over the last $2 \mathrm{myr}$ a better match with orbital models could be obtained with a time scale departing from the established SPECMAP time scale below 620 ka (isotopic stage 16 as defined by Shackleton and Opdyke [1973]. As a consequence, the Brunhes/Matuyama boundary was dated at $780 \mathrm{ka}$ instead of $730 \mathrm{ka}$ as mentioned above.

\section{A SIMPLE MODEL}

In this work, two different models are used to relate the $\delta^{18} \mathrm{O}$ data (that are assumed to rep-

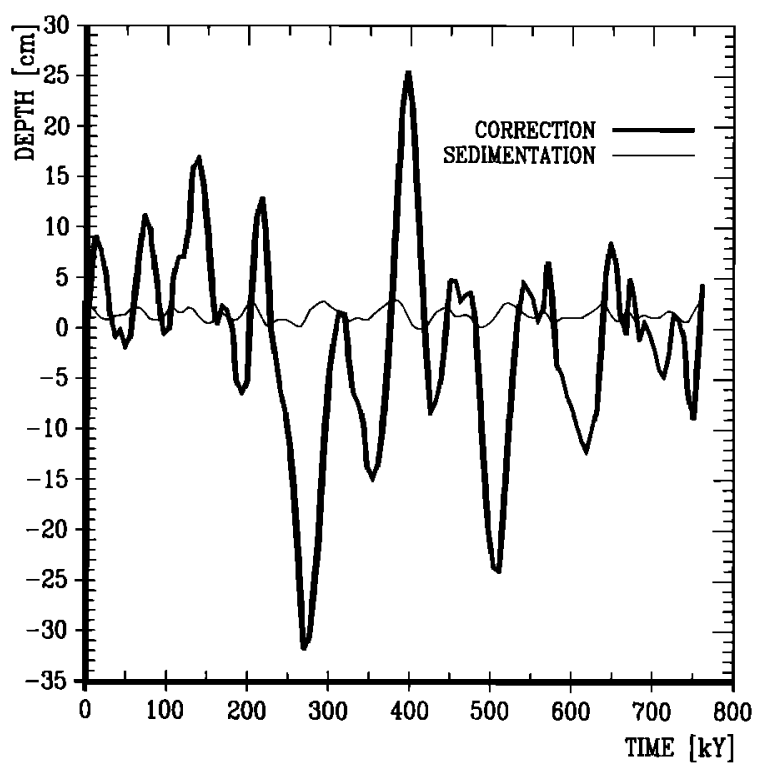

Fig. 3. The optimal correction $x$ to the first guess age-depth function (bold line). The thin line shows the sedimentation rate for the standard run. 
resent global ice volume) and the assumed solar forcing $r(t)$ or $R(f)$. (In the following, time series are denoted by lower case letters in the time domain and upper case letters in the frequency domain. All time series are furthermore assumed to be normalized to zero mean and unit standard deviation.) In the first case, an arbitrary linear model is introduced that can be described by its impulse or frequency response functions $h$ and $H$, respectively. The output of this system, the theoretical global ice volume, $y$ or $Y$, is represented by the convolution of the impulse response function and the input $r$

$y(t)=\int_{-\infty}^{\infty} h(t-u) r(u) d u$

or equivalently by the product of frequency response function and input representation in the frequency domain

$Y(f)=H(f) R(f)$.

In the second case, we consider a preferred model with response functions $h_{0}$ or $H_{0}$ that is typically of low order and can be specified by a stochastic differential equation. For the following we assume for simplicity and consistency with Hasse]mann and Herterich [1983] and Herterich [1988]. that the output, $y_{0}$ or $Y_{0}$, of this preferred system is given by

$\frac{d}{d t} y_{0}(t)=-\lambda_{y_{0}}(t)+\alpha r(t)$,

although linear systems of higher order are also permissible and can be easily implemented in the numerical method used. Here $\alpha$ and $\lambda$ are parameters of the preferred model that can also be used for improving the fit. The frequency response function of the preferred system (3) is given by

$H_{0}(f)=\frac{\alpha}{2 \pi i f+\lambda}$.

The variance of the output time series of these two models, $y$ and $y_{0}$, will be compared with the variance of the core data.

\section{DATA}

Oxygen isotopes ratios recorded from foraminifera are strongly correlated to global ice volume and can be used as an indicator for ice ages [Shack- leton and Opdyke, 1973]. The data obtained from deep-sea cores are expressed in the usual $\delta$ notation related to the PDB standard and are given as a function of depth in the core by

$\delta^{18} \mathrm{O}(c):=\frac{{ }^{18} \mathrm{O} /{ }^{16} \mathrm{O}_{\text {standard }}-{ }^{18} \mathrm{O} /{ }^{16} \mathrm{O}_{\text {sample }}(c)}{{ }^{18} \mathrm{O} /{ }^{16} \mathrm{O}_{\text {standard }}}$.

Linear interpolation is used to complete the $\delta^{18} \mathrm{O}$ curve between actually sampled points in the
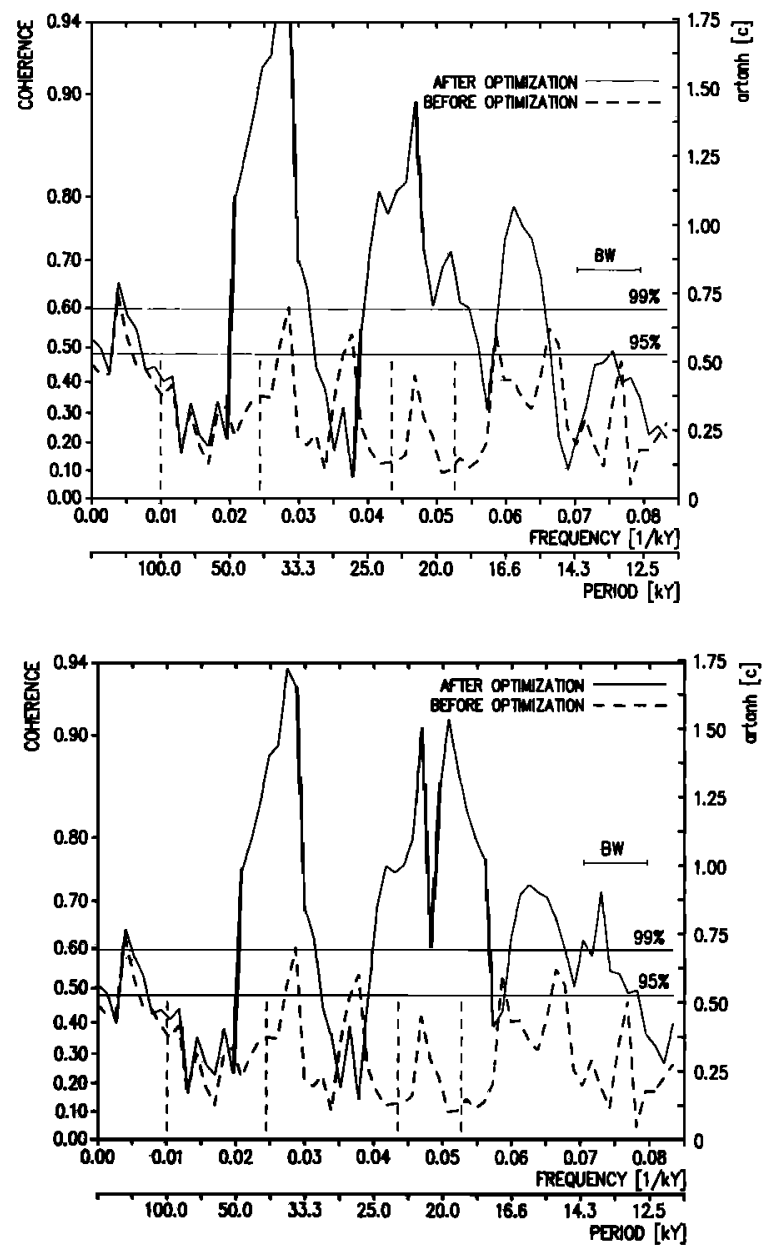

Fig. 4. Coherence between system input (solar insolation) and $\delta^{18} \mathrm{O}$ before (dashed line) and after (solid line) optimization. In the top panel the case with constraints on the parameters of the preferred model $(\lambda>0$ and $a>0)$ is shown, while the unconstraint result is given in the bottom panel. Horizontal lines indicate the $95 \%$ and $99 \%$ confidence limits on an artanh scale [cf. Jenkins and Watts, 1968]. 
core. In Figure 1 the normalized $\delta^{18} \mathrm{O}$ values of the core M 13519 from the Sierra Leone Rise $\left(5^{\circ} 39,5^{\prime} \mathrm{N}, 19^{\circ} 51^{\prime} \mathrm{W}\right)$ are plotted versus depth [Sarnthein et al., 1984].

To test theories of ice ages, the isotopic data must be converted from depth to time-dependent data. Starting from an initial first guess agedepth relation $c_{0}$, we introduce a correction $x$ to obtain a new age-cleptlo function

$c_{\text {new }}(t)=c_{0}(t)+x(t)$.

The data curve then becomes a function of time and the age-depth correction $x$

$$
\begin{aligned}
y_{d a t}(x, t) & =\delta^{18} \mathrm{O}\left(c_{n \epsilon w}(t)\right) \\
& =\delta^{18} \mathrm{O}\left(c_{\mathbf{0}}(t)+x(t)\right) .
\end{aligned}
$$

In the following, the physical length of the core is denoted by $l$ and this point is assumed to be welldated at time $\tau$. The value $t=0$ corresponds to the present condition. The first guess age-depth relation $c_{0}$ and the correction term $x$ are assumed to satisfy

$c_{0}(0)=0 \approx x(0)$

$c_{\text {new }}(-\tau)=c_{0}(-\tau)+x(-\tau) \approx l$.

It should be noted here that $y_{d a t}$ is subject to different types of error. These include sampling errors within the core (i.e., errors associated with the selected sampling interval), disturbances due to the process of coring and in situ disturbances at the ocean floor (e.g., bjoturbulence and changes in currents). Thus $y_{d a t}$ is only one realization of the theoretically infinite ensemble of realizations of the stochastic process underlying the clata. The fitting of the data $y_{\text {dat }}$ to the model output is done in the spectral domain. Averaging over neighboring frequencies of the full resolution sample spectra (or, equivalently, over chunks using corresponding time windows) is used to obtain consistent estimators of the power and cross spectra. In the following, averaging is performed with moving averages always computed over seven frequencies (14 clegrees of freedom). This averaging process is denoted by cornered parentheses $<\cdot>$.

In the standard case the variation of the solar insolation at $65^{\circ} \mathrm{N}$ at July 15 is used as system input, since the solar insolation during the summer
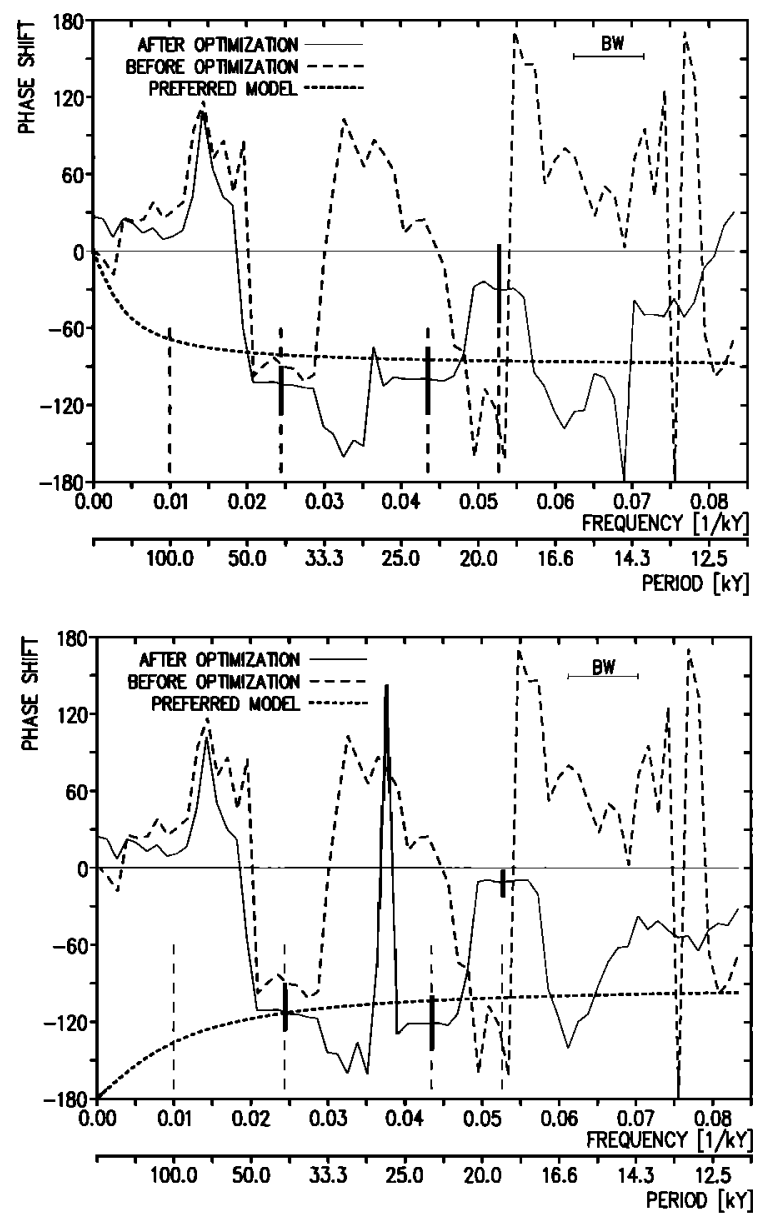

Fig. 5. Phase shifts of the data against system input before (dashed lines) and after (solid lines) optimization procedure with constraints (top panel) and without constraints (bottom) on the parameters of the preferred model as in Figure 4. The dotted line shows the preferred model.

at high northern latitudes is believed to be crucial for ice buildup (cf. Milankovitch [1938] or more recently Crowley and North [1991]). The numerical computation of the solar insolation at a given time uses the method of Berger [1978].

\section{OBJECTIVE FUNCTION}

In this section we establish the objective function for the minimization problem following the original iclea by Hasselmann and IJerterich [1983]. The objective function $F$ consists of the weighted sum 
$F=\sum_{\imath=1}^{6} g_{\imath} F_{\imath}$

of six terms $F_{1}$ to $F_{6}$. Each of these terms represents a different quantified prejudice about the principal features of the final solution. The numbers $g_{1}$ to $g_{6}$ serve two purposes: First, they reflect the individual preference regarding the relative importance of the different components. Seconcl, they are used to normalize the different components for numerical stability of the optimization proceclure. The sensitivity of the optimization problem to changes in the weights is discussed later.

The first term represents the mean square difference between model output $y$ and data $y_{d a t}$

$\left.F_{1}=\int_{-\tau}^{0}<\left(y(t)-y_{d a t}(x, t)\right)^{2}\right\rangle d t$

which is equivalent to the classical coherence maximization criterion as considered in many other investigations [e.g., Martinson et al., 1982]. The averaging over neighboring frequencies of the full resolution sample spectra or the equivalent local averaging process in the time domain indicated by $<\cdot>$ (as an estimation of a hypothetical statistical ensemble average) is redundant here but is introduced as it will be required later for cross spectrum estimation in computing the transfer function $H$ of an optimally fitted linear system.

Second, the corrected age-deptl] function should not deviate too strongly from the first guess $c_{0}$ (see equation (5)). This requirement is expressed by the next component

$F_{2}=\int_{-\tau}^{0} x(t)^{2} d t$.

Furthermore, the correction function should be as smooth as possible and, in particular, it should not contain sharp peaks which would permit the "swallowing" of complete cycles of the data at times where there is little energy in the data. Therefore the third penalty term is

$F_{3}=\int_{-\tau}^{0}\left(\frac{d^{2} x(t)}{d t^{2}}\right)^{2} d t$.

As mentioned allove, certain layers in the core may already be well-clated by other (possibly radiometric) methods (e.g., Brunhes/Matuyama boundary). Such well-dated points should not be changed substantially in the optimized age-depth function. Thus a fourth penalty component

$F_{4}=\sum_{k=1}^{K}\left(c_{k}-c_{n e w}\left(t_{k}\right)\right)^{2}$

is introduced, where $c_{k}, t_{k}(k=1, \ldots, K)$ denote the depths and times, respectively, of well-dated points.

The optimal linear model should be consistent with and provide some information about a plausible physical model. Without this restriction, the transfer function of an arbitrary linear model might differ substantially in adjacent frequencies. In this situation it would be difficult to explain the mechanism linking solar insolation to global ice volume by a simpler model of low order. Therefore the choice of the optimal linear model of arbitrary high order is restricted to a smaller subset of models that have reasonable phase shifts in adjacent frequencies. Imbrie et al. [1989] investigate the question of space-dependent phase shifts which also assumes some reasonably continuous behavior of the transfer functions. Thus we require through the fifth penalty term that the model should be close to the preferred model or,

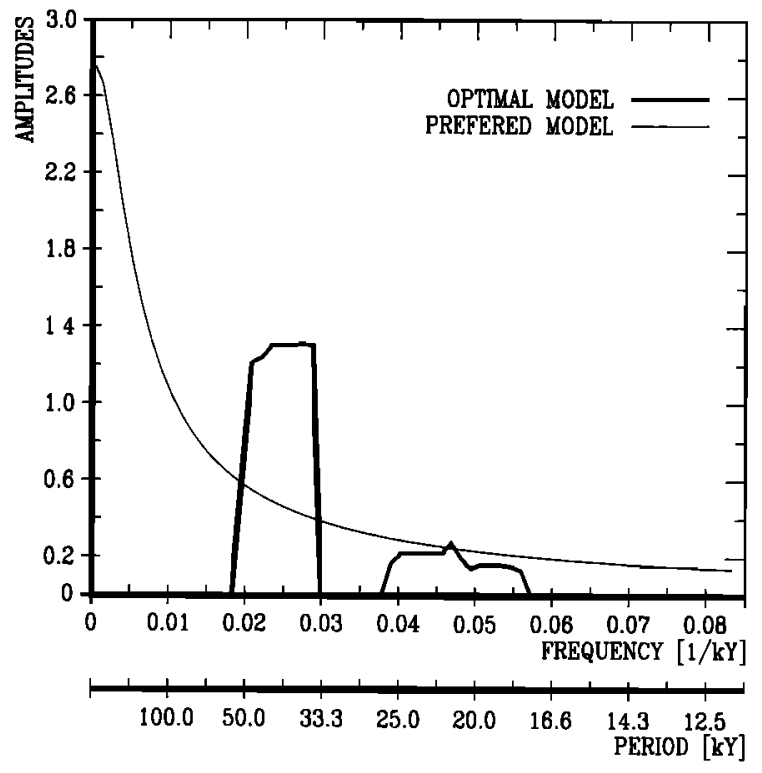

Fig. 6. Optimal transfer function (bold line) plotted only where the system input contains significant energy and the transfer function of the preferred model given by equation (4) (thin line). 
generally, to a model class of low differential order characterized by a finite number of parameters (e.g., see equation (3) with two parameters $\alpha$ and $\lambda)$,

$F_{5}=\sum_{\jmath=-\infty}^{\infty}<\left|R\left(f_{\jmath}\right)\right|^{2}>\left|H\left(f_{\jmath}\right)-H_{0}\left(f_{\jmath}\right)\right|^{2}$.

The first five components of the objective function are essentially the same as suggested by Hasselmann and Herterich [1983]. For practical purposes (especially if the weight $g_{1}$ is chosen to be large) it is necessary to include a sixth condition that prevents the age-depth relation from reversing in time. Thus a very large penalty is introduced for age-depth functions which do not increase monotonically:

$F_{6}=\int_{-\tau}^{0}\left(\chi(t) \frac{d}{d t} c_{n e w}(t)\right)^{2} d t$

where

$$
\begin{array}{ll}
\chi(t)=1 & \frac{d}{d t} c_{n \epsilon w}(t) \leq 0 \\
\chi(t)=0 & \text { otherwise. }
\end{array}
$$

In addition to these requirements one could specify a preferred value or range for the parameters of the preferred model. For example, negative $\alpha$ and $\lambda$ in the preferred model (3) are physically meaningless. Again, such constraints can be formulated as least squares terms and added to the objective function with appropriate weights.

In summary, we construct an objective function

$F(x, H, \alpha, \lambda)=\sum_{i=1}^{6} g_{\imath} F_{\imath}(x, H, \alpha, \lambda)$,

that depends on the age-depth correction $x$, the optimal transfer function $H$ and the parameters of the preferred system (which we will take in the following to be $\alpha$ and $\lambda$ in accordance with the first-order preferred model given in (3)). For given values of the correction $x(t)$ and the parameters $\alpha$ and $\lambda$, the optimal transfer function can be computed analytically at every frequency (since we consider only a finite interval of data, the variables in the frequency domain are discrete with $\Delta f=1 / \tau)$. From the standard minimal condition we obtain

$$
\begin{aligned}
H\left(f_{J}\right) & =\frac{g_{1}<\overline{R\left(f_{\jmath}\right)} Y_{d a t}\left(x, f_{\jmath}\right)>}{<\left|R\left(f_{\jmath}\right)\right|^{2}>\left(g_{1}+g_{5}\right)} \\
& +\frac{g_{5} H_{0}\left(f_{\jmath}\right)<\left|R\left(f_{3}\right)\right|^{2}>}{<\left|R\left(f_{\jmath}\right)\right|^{2}>\left(g_{1}+g_{5}\right)},
\end{aligned}
$$
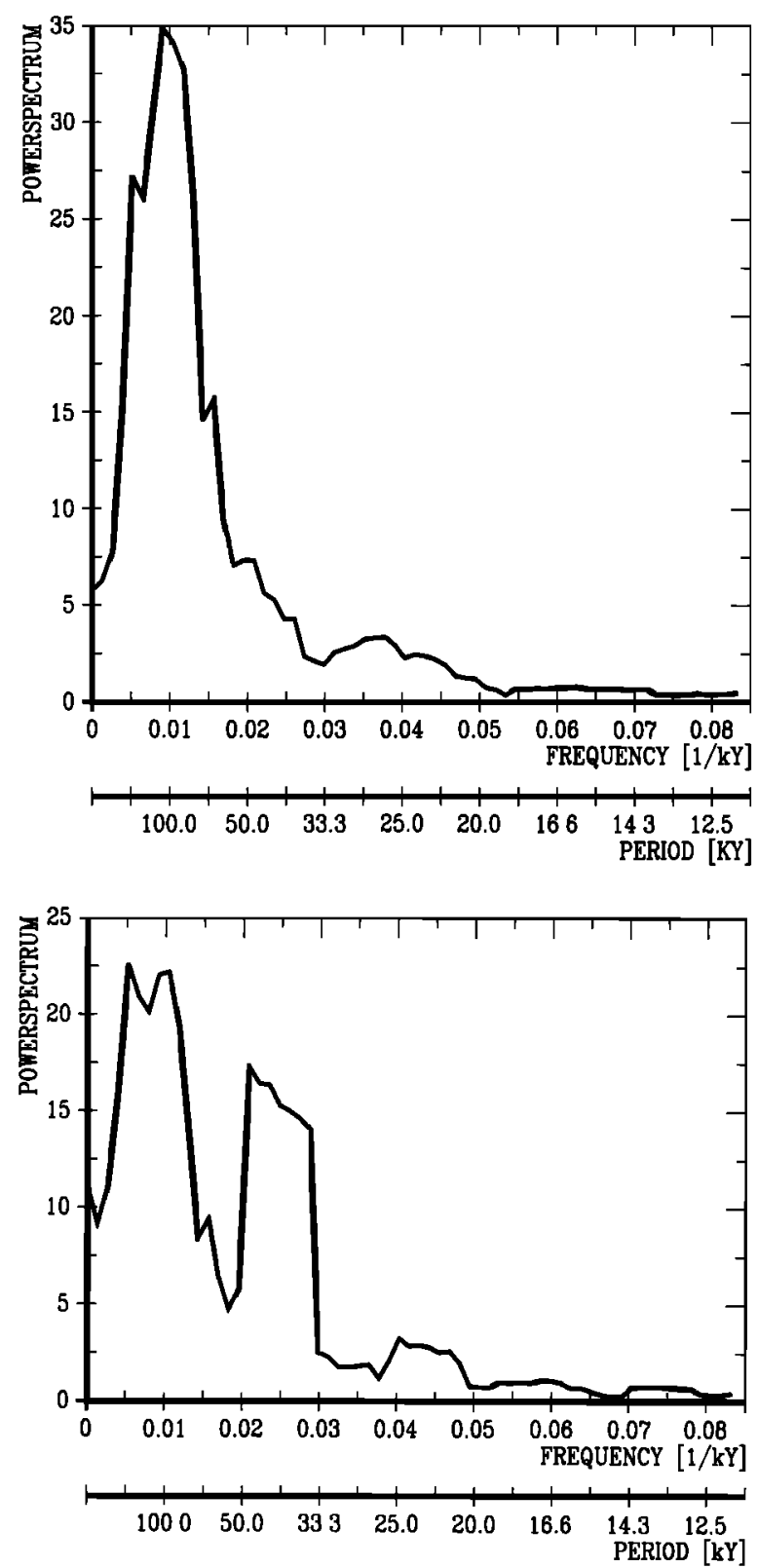

Fig. 7. Power spectra estimates for the $\delta^{18} \mathrm{O}$ time series before (top) and after (bottom) optimization. It should be noted that for clarity the spectral estimates are plotted here on a linear scale in contrast to the power spectra shown in Figure 10 till Figure 15, which were plotted on a logarithmic scale as suggested by Jenkins and Watts [1968]. 
where the overbar denotes complex conjugates.

For $g_{5}=0$ one recovers the standard optimal linear model solution. In the case that both parameters $g_{1}$ and $g_{5}$ are positive, the numerator in equation (14) incluces a shift from the estimator of the cross spectrum $<\overline{R\left(f_{\jmath}\right)} Y_{d a t}\left(x, f_{1}\right)>$ towards the transfer function of the preferred system $H_{0}\left(f_{j}\right)$. Substitution of the optimal transfer function (14) into the objective function (13) yields then a simpler cost function

$F(x, \alpha, \lambda)=\sum_{\imath=1}^{6} g_{\imath} F_{\imath}(x, \alpha, \lambda)$,

that clepends only on the correction $x(t)$ and the paramelers $a$ and $\lambda$.

\section{NUMERICAL RESULTS}

The discretization of the objective function $F$ in equation (15) which is necessary for the numerical optimization is presented in the appendix. In the following, we shall consider some typical applications with $M+2=130$ independent variables consisting of 128 time node components $(\Delta t=$ $6 \mathrm{kyr}$ which allows a straightforward application of stanclard fast Fourier transform (FFT) algorithms) and two components representing the parameters $\alpha$ and $\lambda$ of the preferred model.

\section{Standard Case}

As a standard case we consider the $\delta^{18} \mathrm{O}$ data from the Meteor core M 13519 (Figure 1) [Sarnthein et al., 1984]. Starting from a linear interpolation between the present and the Brunhes/Matuyama boundary at $730 \mathrm{ka}$ as the first guess age-depth function, the optimization procedure produces a correction that shifts certain time nodes up to $24 \mathrm{kyr}(32 \mathrm{~cm})$ in the core. In the following, the resulting age-depth function shown in Figure 2 is referred to as the standard run. The net correction (Figure 3 ) has large variations with typical cycle lengths in a broad frequency band at approximately $100 \mathrm{kyr}$ (more precisely with peaks at 80 and $250 \mathrm{kyr}$ ).

Martinson et àl. [1982] investigate a similar situation with artificial clata sets and arrive at a distorted signal that shows a saw-toothed shape similar to that of the original $\delta^{18} \mathrm{O}$ function. This distorted signal was obtained by passing the original sinusoiclal signal through a mapping function
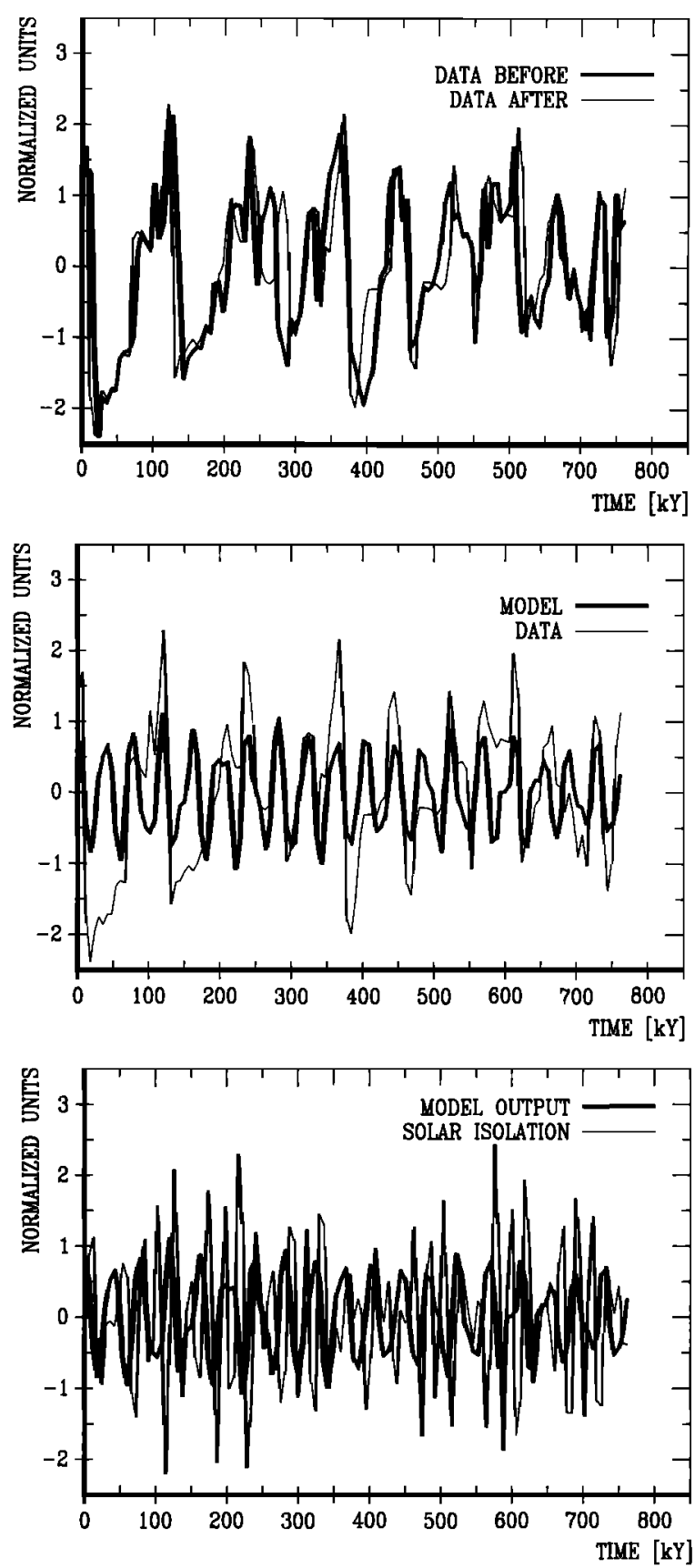

Fig. 8. The top panel shows the data curves before and after optimization, while in the middle the data time series is plotted versus model output, which can be seen at the bottom again compared to solar insolation. 


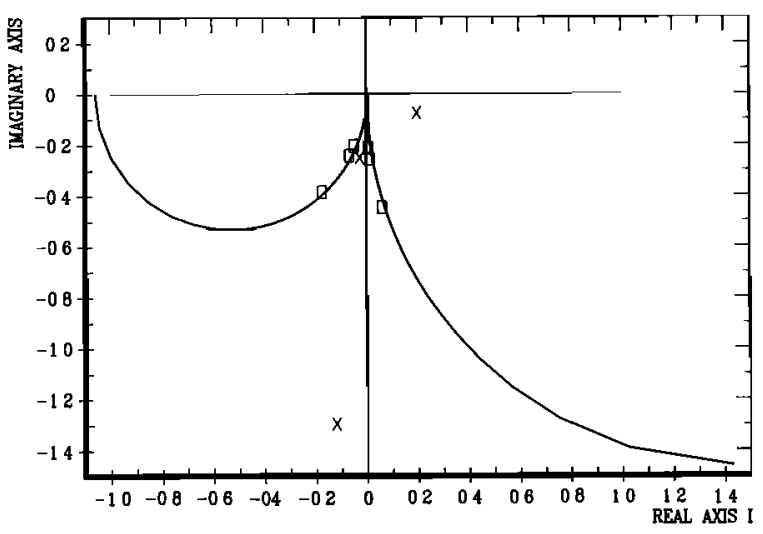

Fig. 9. Optimal transfer function (indicated by the crosses for the Milankovitch frequencies) and preferred transfer function (full lines). The full line on the right hand side is the transfer function of the preferred model for $\lambda=0.024$ and $\alpha=0.07$. The full line on the left-hand side shows the graph of formula (4) for $\lambda=-0.06$. The distance between the optimal and the preferred transfer function does not depend strongly on the sign of $\lambda$.

which consists of a linear trend modified by an oscillatory component in the same frequency as the signal. Martinson et al. [1982] concluded that a nonlinear, oscillatory mapping function might arise when the recording process itself is somewhat sensitive to fluctuations in the signal. This is precisely the case in this situation where the sedimentation rate (recording process) is indeed sensitive to climate state (signal).

For the standard run age-depth relation, coherence values between data and solar insolation are obtained that exceed the $99 \%$ conficlence limits in all three Milankovitch frequency bands 19 , 23, and $41 \mathrm{kyr}$ (cf. top panel in Figure 4). It is important to note that the coherences obtained are dependent upon the averaging procedure used. In this work, averages of the full resolution sample spectra were computed over a relatively wide range of frequencies (14 real degrees of freedom). In general, the confidence levels at a given frequency for stochastic estimators associated with a certain averaging technique depend not only on the number of degrees of freedom used for averaging but also on the bandwidth of the spectra at that frequency. In this case the bandwidth of solar insolation at, for example, $41 \mathrm{kyr}$ is not as wide as the frequency range used for averaging. Thus the confidence limits for coherence depend in our case on frequency. For simplicity and comparability with other investigations [e.g., Imbrie et al., 1984] the standard confidence limits in ac-

TABLE 1. Ages of Isotopic Events

\begin{tabular}{crrrr}
\hline Isotopic Events & Depth, cm & \multicolumn{3}{c}{ Age, ka } \\
\cline { 2 - 5 } & & Herterich & Imbrie & Brüggemann \\
\hline 0.0 & 0.0 & 0.0 & 0.0 & 0.0 \\
1.1 & 14.0 & 9.0 & 6.0 & 5.9 \\
2.0 & 26.0 & 16.4 & 12.0 & 12.5 \\
2.2 & 32.0 & 20.3 & 19.0 & 18.0 \\
3.0 & 36.4 & 22.9 & 24.0 & 22.8 \\
3.1 & 42.8 & 27.0 & 28.0 & 31.0 \\
3.3 & 80.0 & 52.2 & 53.0 & 58.1 \\
4.0 & 90.7 & 60.2 & 59.0 & 63.2 \\
5.0 & 96.3 & 64.5 & 71.0 & 65.9 \\
5.1 & 115.0 & 79.5 & 80.0 & 78.0 \\
5.2 & 128.4 & 90.4 & 87.0 & 95.3 \\
5.3 & 138.0 & 98.0 & 99.0 & 102.2 \\
5.4 & 145.3 & 103.5 & 107.0 & 105.6 \\
5.5 & 168.6 & 120.0 & 122.0 & 119.7 \\
6.0 & 184.0 & 129.7 & 128.0 & 127.6 \\
\hline
\end{tabular}

Isotopic event data from Prell et al. [1986]. Ages are given for events in core Meteor M 13519 during the last $130 \mathrm{kyr}$. The core data and the third column are taken from Herterich [1988], while the fourth column shows the SPECMAP results given by Imbrie et al. [1984]. 
TABLE 2. Ages of Isotopic Events

\begin{tabular}{crrrrrrr}
\hline Isotopic Event & Depth, cm & \multicolumn{7}{c}{ Age, ka } \\
\cline { 3 - 7 } & & CAR. & TUNE & STUNE & SHACK & SPEC. & Brüggemann \\
\hline $1 / 2$ & 24.0 & 13 & 17 & 10 & 13 & 12 & 11 \\
$2 / 3$ & 38.0 & 27 & 31 & 18 & 32 & 24 & 25 \\
$3 / 4$ & 83.0 & 56 & 73 & 49 & 64 & 59 & 60 \\
$4 / 5$ & 98.0 & 70 & 86 & 63 & 75 & 71 & 67 \\
$5 / 6$ & 184.0 & 127 & 139 & 127 & 128 & 128 & 128 \\
$6 / 7$ & 277.0 & 209 & 195 & 184 & 203 & 186 & 203 \\
$7 / 8$ & 370.0 & 277 & 260 & 244 & 262 & 245 & 289 \\
$8 / 9$ & 416.0 & 312 & 290 & 269 & 310 & 303 & 306 \\
$9 / 10$ & 506.0 & 374 & 348 & 332 & 362 & 339 & 375 \\
$10 / 11$ & 558.0 & 410 & 381 & 369 & 383 & 362 & 395 \\
$11 / 12$ & 622.0 & 444 & 420 & 409 & 459 & 423 & 458 \\
$12 / 13$ & 685.0 & 510 & 478 & 475 & 492 & 478 & 519 \\
$13 / 14$ & 744.0 & 540 & 526 & 527 & 524 & 524 & 549 \\
$14 / 15$ & 758.0 & 551 & 537 & 539 & 565 & 565 & 560 \\
$15 / 16$ & 829.0 & 608 & 591 & 598 & 617 & 620 & 622 \\
$16 / 17$ & 884.0 & 657 & 635 & 644 & 654 & 659 & 649 \\
$17 / 18$ & 916.0 & 678 & 658 & 668 & 675 & 689 & 677 \\
$18 / 19$ & 968.0 & 712 & 701 & 712 & 712 & 726 & 719 \\
$19 / 20$ & 996.0 & 733 & 720 & 730 & 736 & 736 & 739 \\
\hline
\end{tabular}

Ages of the stage boundaries (defined by Shackleton and Opdyke [1973]) in core Meteor M 13519 for the full length of the core. The depths are taken from Sarnthein et al. [1984]. The three tuning approaches CARPOR (CAR.), TUNE and STUNE are given by Herterich and Sarnthein [1984] which also lists the SHACK data from Shackleton and Matthews [1977]. The SPECMAP (SPEC.) age-depth function is given by Imbrie et al. [1984].

cordance with Jenkins and Watts [1968] have been given in Figure 4.

The phase shifts of the data relative to the solar insolation (top panel in Figure 5) are negative in the Milankovitch frequencies. This is a necessary condition for our linear model to be causal (it implies that the physical quantity represented by the data follows the solar insolation). On the other hand, the phase shifts at 41 and 23 kyr are larger than the shift at $19 \mathrm{kyr}$, which implies instability in the case of a first-order model (for models of arbitrary high order, as for example $H$, this does not violate any stability condition). However, the 95\% confidence limits for the phase shifts, which depend on the associated coherence [Jenkins and Watts, 1968], extend to the phase shift curve of the preferred model, which is given by

$\psi(f)=\arctan \left(\frac{-2 \pi f}{\lambda}\right)$.

It should be stressed that other investigations [e.g., Martinson et al., 1982] have had the sole aim of maximizing either the coherence or the phase agreement with some preferred model. This is not the case here. In our study, coherency maximization is restricted by requiring that the optimal frequency response function should not deviate too far from the preferred model or moclel class. In order to maximize the coherence between data and solar insolation, the weight $g_{5}$ in (15) should be small compared to $g_{1}$. The transfer function (14) is then dominated by the cross spectrum of input and clata and the coherence approaches the maximum possible value for an arbitrary linear model. If, on the other hand, the weight $g_{5}$ is chosen relatively large compared to the other weights, the optimal transfer function will be dominated by the frequency response function of the preferred model, and the agreement in phase with the preferred model will be good, at the expense of the coherence [cf. Herterich 1988].

The amplitudes of the transfer functions are plotted in Figure 6, while the data spectra before and after optimization are shown in Figure 7. 
By using a sedimentation rate which varies on the same time scale as the ice ages, a transfer of energy can be observed from the $100 \mathrm{kyr}$ cycle band of the data spectrum before optimization into the 41,23 , and $19 \mathrm{kyr}$ frequency bands of the spectrum after the optimization process. The sedimentation rate varies between approximately 0 and $3 \mathrm{~cm} / \mathrm{kyr}$. The effects on the original data of this correction to the initial age-depth function can be seen in the top panel of Figure 8. The two remaining panels show the output of the optimally determined linear model of arbitrary high order compared to the data after optimization (middle panel) and the system input solar insolation (bottom).

The data spectrum before optimization contains significant energy only in the 100 kyr frequency band (Figure 7 , top panel). After the age-depth function has been optimally adjusted, the data spectrum also contains energy in the Milankovitch frequencies (cf. Figure 7, bottom panel). However, a large part of the data variance cannot be explained by a linear model with input solar insolation. This result is not surprising considering the large climate response and negligible solar forcing in the $100 \mathrm{kyr}$ band. Imbrie and Imbrie [1980] and Martinson et al. [1987] have suggested for this reason the use of a nonlinear model consisting of two different linear models for cooling and warming periods, an approach which is motivated by the typical asymmetric shape of the data curves. As already mentioned above, this saw-toothed shape of the data curve may in part be explained by the dependence of the sedimentation rate on the climate state [Martinson et al., 1982]. However, it should be noted that spectral power of the sinusoidal data by Martinson et al. [19\$2] was transferred by the oscillatory mapping function only into frequencies which

Fig. 10. Results for application of the method presented to case 1 (i.e.. SPECMAP stack with the standard first guess age-depth function and tuning target solar insolation). The top panel shows the spectra before (thin line) and after optimization (bold line), while the associated coherences are shown in the middle panel. At the bottom the optimized data curve and the SPECMAP stack are plotted versus time.
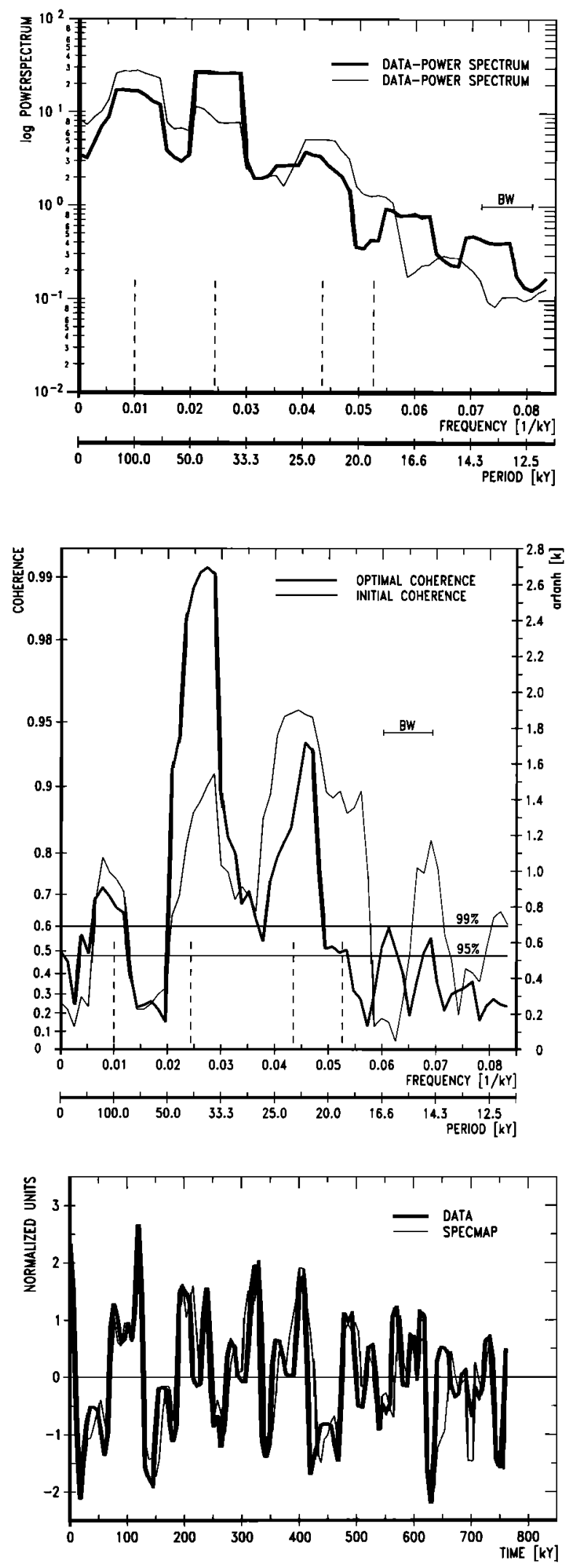

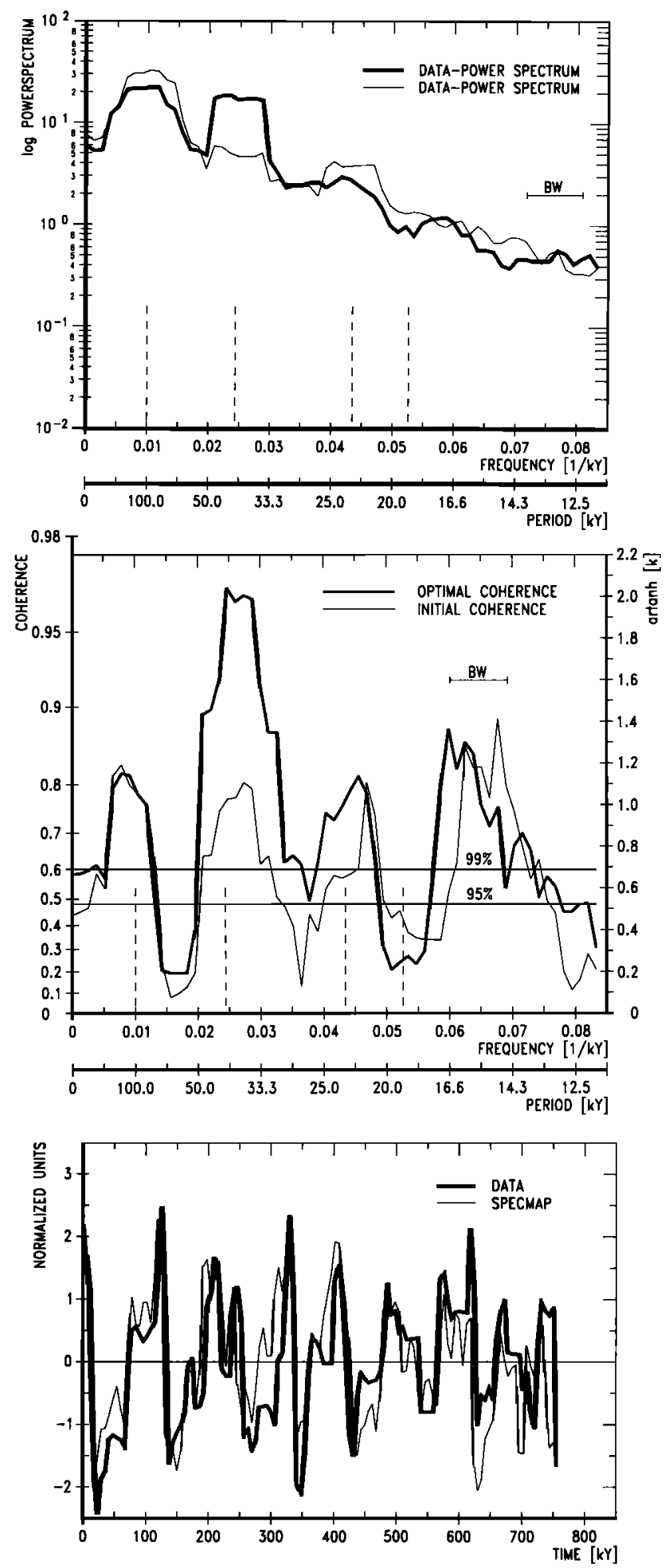

Fig. 11. As for Figure 10, but for case 2 (i.e., core M 13519 with a first guess age-depth function given by a linear interpolation between isotopic stage boundaries dated by the SPECMAP calibration). were multiples of the original frequency. Thus it would be difficult to explain a shift of power from $100 \mathrm{kyr}$ to the Milankovitch frequencies at 41,23 , and $19 \mathrm{kyr}$ as observed here. Moreover, the combination of an oscillatory age-deptl relation and a linear model does not account for the fact that most of the power in the data spectrum is contained in the $100 \mathrm{kyr}$ cycle where there is no significant power in the system input. Therefore since a. considerable amount of the data variance cannot be satisfactorily explained by a linear model, the least squares function (15) leads to a minimization problem with large residuals. The value of the objective function at the optimal solution is approximately $65 \%$ of the value at the starting point.

For a physically plausible interpretation of the preferred model the parameters $\alpha$ and $\lambda$ must be positive. Positive $\lambda$ is required for stability of the preferred system, while positive $\alpha$ implies smaller ice sheets for larger insolation. Yet the mathematical problem of minimizing objective function $F$ in (17) is well posed even for arbitrary $\alpha$ and $\lambda$. If, for the sake of simplicity, the optimization is carried out without restricting $\alpha$ und $\lambda$ to positive values, the optimal solution found yields negative values for both parameters of the preferred model indicating that a first-order Markov process such as (3) cloes not suffice to describe the system in a satisfactory manner. The coherences between data and system input obtained in this situation are obviously higher than in the constrajnt case that the parameters $\alpha$ and $\lambda$ are forced to be positive. If $\lambda$ is allowed to become less than zero, the fifth component of the objective function (11) then no longer represents the distance between the frequency response function $H$ and the transfer function of a physical preferred system but gives instead an approximation target for $H$ in form of a complex function of frequency that depends in addition on two parameters. The actual position in the complex plane of the optimal transfer function in the Milankovitch frequencies does not depend strongly on the sign of $\lambda$ (Figure 9). Experiments (Figures 4 and 5) show that the influence of the sign (i.e., the shape of the complex approximation target) on the resulting age-depth relation and the obtained coherences and phase shifts is rather small. This is due to the fact that the preferred model is rather meant to control the shape of the optimal transfer function and prevent large 

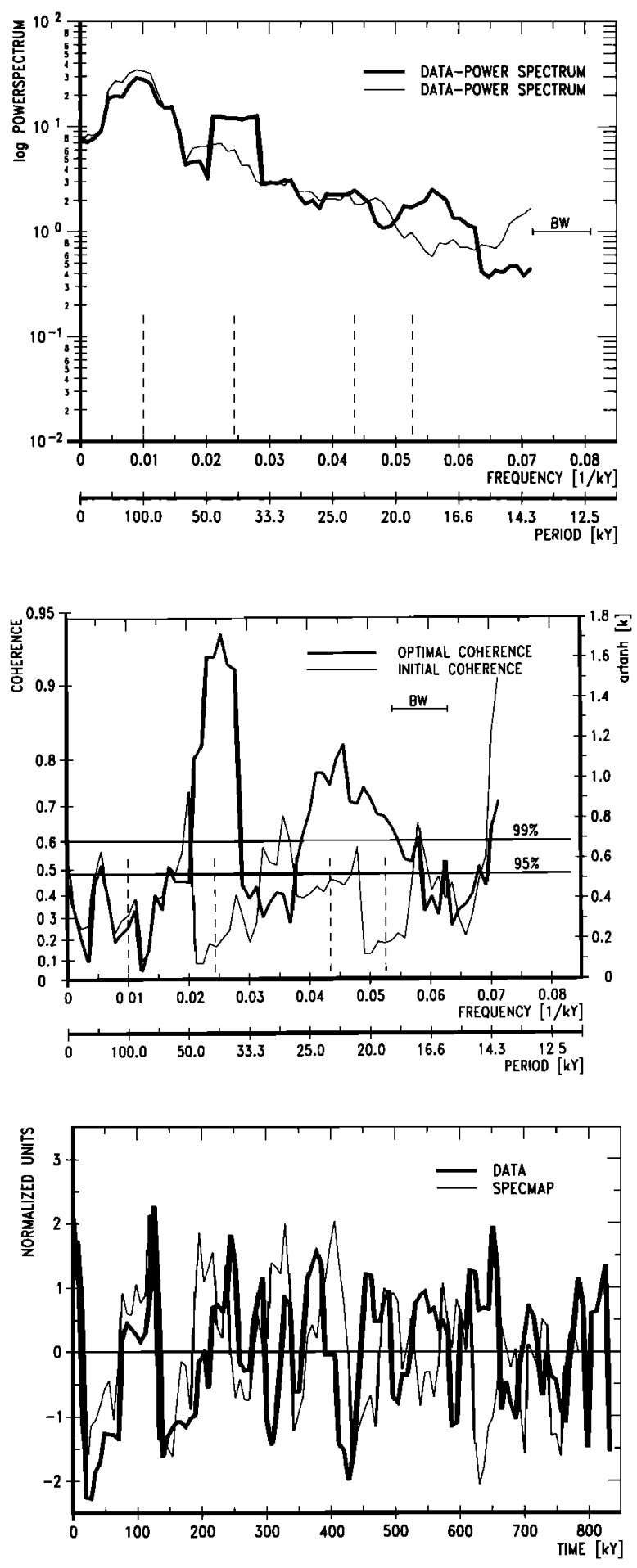

Fig. 12. As for Figure 10, but for case 3 (i.e., core M 13519 with a first guess age-depth function given by a linear interpolation between the present and the redated Brunhes/Matuyama boundary at $780 \mathrm{ka})$. discontinuities in adjacent frequencies than actually force the optimal model in the direction of the preferred model. However, if $\alpha$ is sign-constrained and $1 / \lambda$ is assumed to lie in the interval between 10 and $100 \mathrm{kyr}$, then the optimal time constant obtained is $41.7 \mathrm{kyr}$, while the optimal value for $1 / \lambda$ without further constraints is $-15.2 \mathrm{kyr}$.

The results obtained by this approach for the age-depth function are consistent with earlier investigations. The ages of isotopic events determined in core Meteor M 13519 [Sarnthein et al., 1984] are compared with those obtained by Herterich and Sarnthein [1984], Herterich [1988], Imbrie et al. [1984], and Shackleton and Matthews [1977] in Table 1 (fine temporal resolution for the last ice age cycle) and Table 2 (coarse temporal resolution). The deviations between the different approaches tend to be larger in the center of the time interval considered, away from the well-dated end points. The highest amplitudes in the correction $x$ (see Figure 3) lie in the time interval between 200 and $500 \mathrm{ka}$, in which the greatest deviations between the three different age-depth relations obtained by Herterich and Sarnt hein [1984] are found. Cirieger [1992] achieved an age-depth function very similar to our optimal result in the standard run, despite the fact that he neglected the low-frequency component in his model. Martinson et al. [1987] arrived at age-depth relations for another core that show departures from linearity whiclı are similar to those obtained here in the standard run.

The amplitudes and phase shifts of the data. spectrum against system input are comparable to the values given by Hasselmann and Herterich [1983] for the age-depth relations CARPOR, TUNE, and STUNE.

The maximum coherences obtained (greater than 90\%) are higher than those given by Herterich and Sarnthein [1984] (maximum in single peaks of $75 \%$ squared coherence which corresponds to approximately $85 \%$ coherence), even though coherence is not exclusively maximized in our objective function $F$ in (17). The coherences are slightly lower than those given by Imbrie et al. [1984] for the SPECMAP time scale, although it should be pointed out that the SPECMAP coherences are calculated between an artificial stack and the sum of the normalized orbital parameters (ETP). By using the ETP curve as system input, 
the SPECMAP approach is also able to explain data energy contained in the $100 \mathrm{kyr}$ cycle, where there is no significant energy in solar insolation.
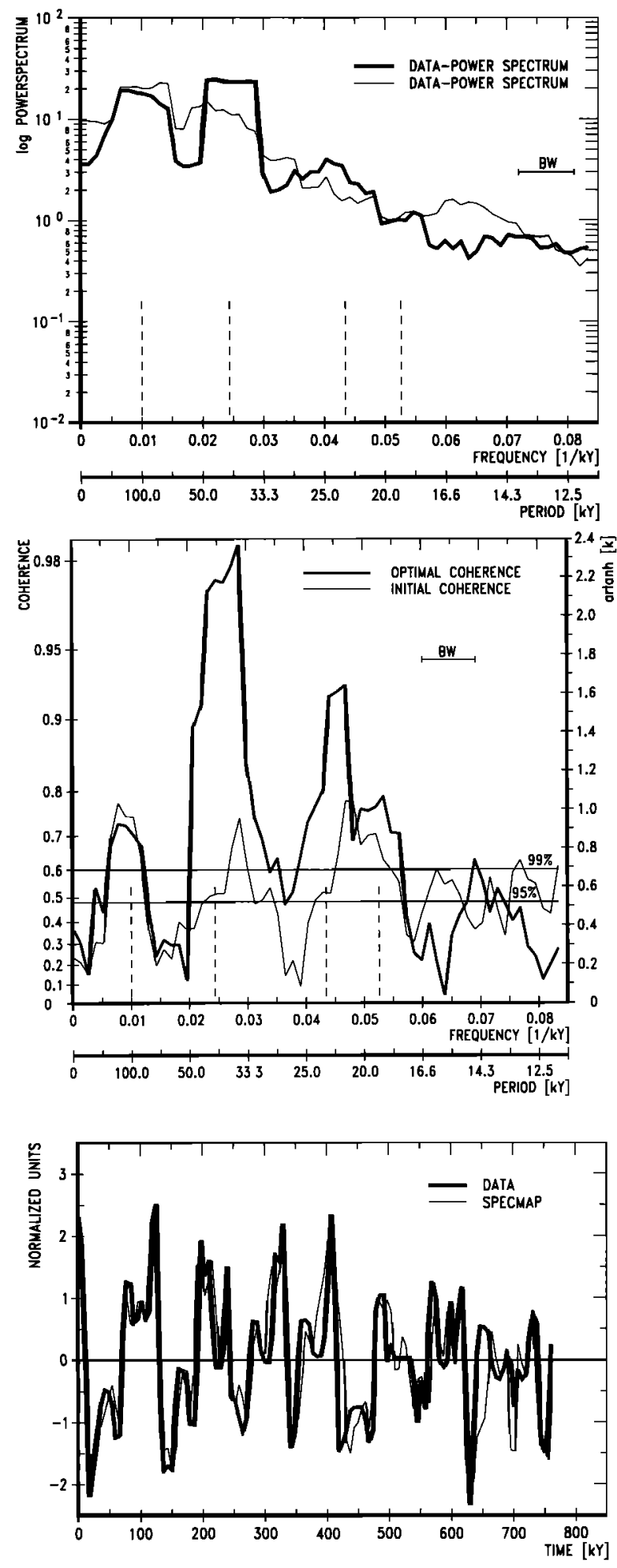

Application to Different Cases

In order to test the method with different combinations of input data series, tuning targets and first guess age-depth functions, we performed sensitivity studies on the following cases:

1. SPECMAP stack with the standard first guess age-depth function and tuning target solar insolation.

2. Core M 13519 with first guess age-depth function given by a linear interpolation between isotopic stage boundaries dated by the SPECMAP calibration.

3. Core M 13519 with a first guess age-depth function given by a linear interpolation between the present and the redated Brunhes/Matuyama boundary at 780 ka with $\Delta t$ increased from 6 to 7 kyr.

4. SPECMAP stack with a first guess agedepth function given by a linear interpolation between isotopic stage boundaries optimally dated by the standard run.

5. SPECMAP stack with a first guess agedepth function given by a linear interpolation between the present and the reclated Brunhes/Matuyama boundary at 780 ka with $\Delta t$ increased from 6 to 7 kyr.

6. SPECMAP stack with the standard first guess age-depth function but the tuning target ETP.

The results (spectra of the data before and after optimization, corresponding coherences and optimized time series compared to the SPECMAP stack) are shown in Figures $10-15$. Note that in the case of ETP-forcing (case 6) it is possible to improve the SPECMAP calibration in terms of the coherences, although this was the SPECMAP optimization criterion. The optimal time constant of the preferred system in this case is $12.8 \mathrm{kyr}$.

The coherences oltained for the SPECMAP case with a first guess age-depth relation taken from the optimal standard run (case 4) are quite

Fig. 13. As for Figure 10, but for case 4 (i.e., SPECMAP stack with a first guess age-depth function given by a linear interpolation between isotopic stage boundaries optimally dated by the standard run). 

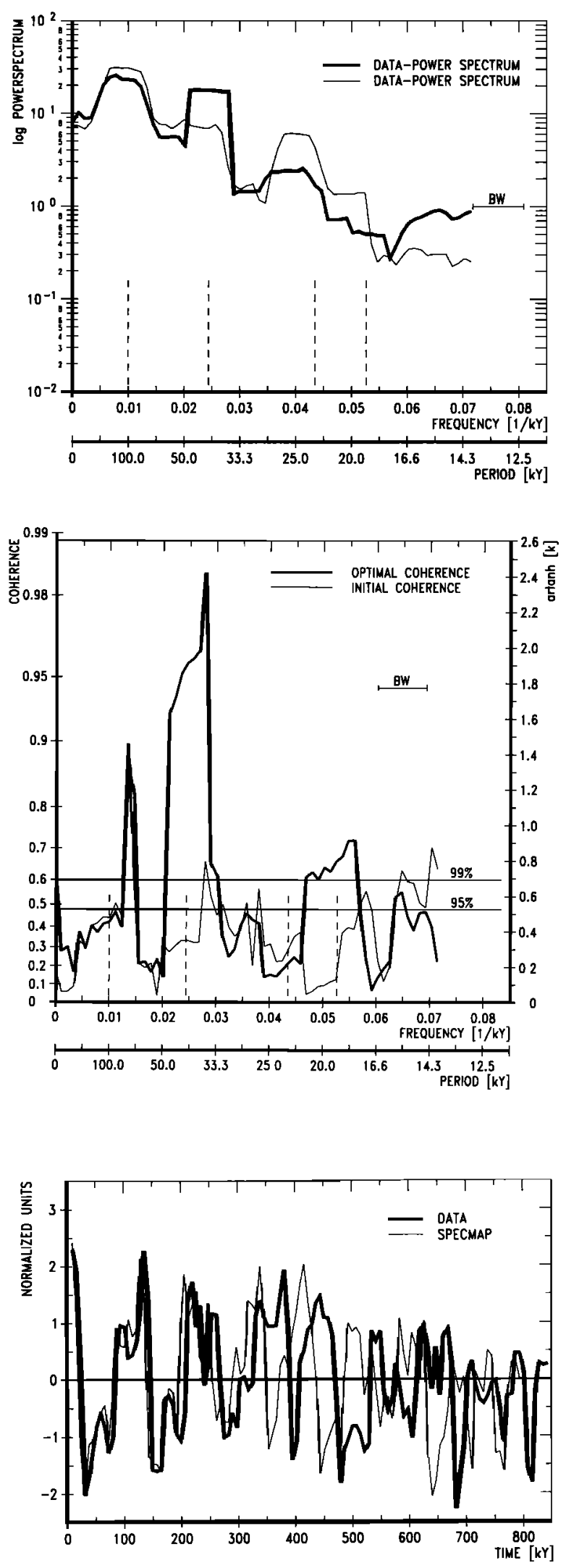

high, although only forcing by solar insolation is consiclered, but do not reach the values obtained in case 6 . This observation and the fact that the optimal solutions for the standard case and case 2 are quite different inclicates the dependence of the final solution on the subjective choice of the first guess age-depth function. Reasonable coherence values were also obtained for the two cases (case 3 and case 5) that were started with a first guess age-depth function that attributes an age of 780 ka to the Brunhes/Matuyama boundary instead of $730 \mathrm{ka}$. This gives further support to the redating of the Brunhes/Matuyama boundary as suggested by Shackleton et al. [1990].

\section{Random Time Series and Sensitivity Analysis}

It has been shown that high coherences in all three Milankovitch frequencies can be obtained for real ocean core data by optimizing the agedepth function. There is naturally a lingering suspicion that this may just be an artifact of the analysis method, and that high coherences could have been generated artificially for any random time series. To rule out this possibility, filtered white noise tests were performed, in which the input time series were generated randomly with a spectrum similar to that of a typical $\delta^{18} \mathrm{O}$ data series (i.e., most energy contained in the $100 \mathrm{kyr}$ frequency band). Again, corrections of a similar shape were produced and a similar energy shift from the $100 \mathrm{kyr}$ to the $41 \mathrm{kyr}$ band could be observed, but significant coherences could be generated in only one frequency band at a time. It was impossible to obtain simultaneously reasonable colerences in all three Milankovitch bands, as found for real ocean core data.

The weights $g_{t}$ served two purposes. First, they were used to normalize the different components of the objective function, which is necessary for numerical stability. Second, they reflect the sub-

Fig. 14. As for Figure 10, but for case 5 (i.e., SPECMAP stack with a first guess age-depth function given by a linear interpolation between the present and the redated Brunhes/Matuyama boundary at $780 \mathrm{ka}$ ). 

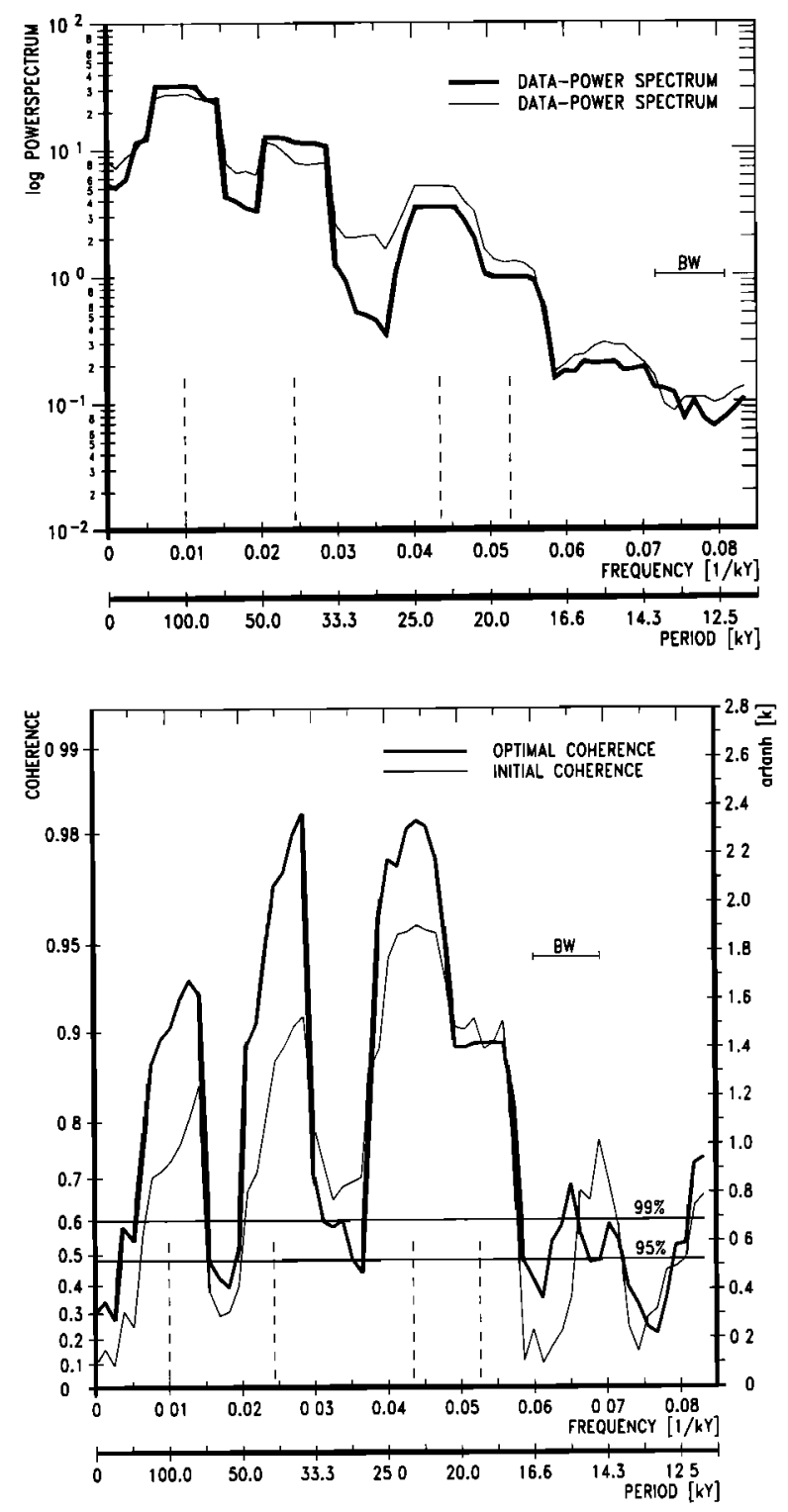

jective judgement of the user as to the respective importance of the different components. For physically meaningful age-depth functions we always selected large values for the weight $g_{6}$. Since the corresponding objective function component is zero for all first guess age-depth functions, this does not contribute to the initial iterations of the objective function and acts only to prevent solutions from becoming nonmonotonic. To test the sensitivity of the minimization problem with respect to the remaining weights $g_{1}, \ldots, g_{5}$ we computed standard case solutions for weights which were individually multiplied by factors

$\frac{1}{100}, \frac{1}{10}, 10,100$

while all other weights were kept at their standard run values. The highest coherences were obtained in the standard run. The basic lowfrequency structure (cycle length of $250 \mathrm{kyr}$ and more) of the optimal age-depth function remains constant throughout the sensitivity analysis, although the high-frecuency details (in this context: cycle lengths at $100 \mathrm{kyr}$ and less) varied considerably. This preliminary sensitivity analysis yields age-depth functions with differently shaped corrections. As expected, a much smoother correction was obtained, when the parameter for the second derivative was increased.

Another question raised above is the influence of the first guess age-depth function on the solution. This chosen fixed function is part of the quantifiable subjectivity of the approach. Since the deviation of the age-clepth function from the first guess is penalized, the results obtained for two different first-guesses will differ if the deviations are large. Different solutions were actually obtained by changing the first guess, as indicated in the case studies discussed above. We performed a further numerical test in which the first guess age-depth relation was altered from a linear function by adding randomly selected corrections drawn from the interval $[-3 \mathrm{~cm}, 3 \mathrm{~cm}]$. The result

Fig. 15. As for Figure 10, but for case 6 (i.e., SPECMAP stack with the standard first guess age-depth function but tuning target ETP). 
from this experiment did not differ significantly from the stanclard run. In general, the optimization problem is more sensitive to the weights than to small, random changes of the first guess agedepth function, although substantial and systematic changes of this function will alter the results considerably (e.g., SPECMAP calibration versus linear interpolation). Thus, if a priori information about the data inclicate that a linear age-depth function is incorrect, this information should be used to determine a better first guess age-depth function. For example, if the linear age-depth function incorrectly maps a peak of the data curve to an input peak, the algorithm is not likely to change this incorrect matching, since the reduction of the cost function by more coherent model and data time series is compensated by the increase in the remaining components of the objective function.

This dependence of the optimal solution on the initial guess is not to be confused with the possibility of arriving at a local minimum which is not the absolute minimum. In general, there is no guarantee that numerical optimization routines will locate the global minimum, although there are algorithms that cope with this problem (e.g., the simulated annealing approach developed by Kirkpatrick et al. [198:3] originating from equation of state calculations in thermodynamics by Metropolis et al. [1953]). Since the objective function is neither quadratic nor convex, we may expect local minima. A typical graph of the objective function for the coherence maximization problem is given by Martinson et al. [1982]. However, the objective function (15) is much smoother here, since, as discussed above, an improvement in one component (e.g., higher coherence by including an additional input cycle at data points of small amplitude) is usually outperformed by the remaining components (e.g., the third component that penalizes large curvature of the correction). Thus the number of local minima is much smaller than in the case considered by Martinson et al. [1982]. The fact that the resulting age-depth function for the standard run shows shifts of time nodes up to $24 \mathrm{kyr}(32 \mathrm{~cm})$ indicates that the optimization procedure can locate solutions with large departures from the initial guess, j.e., that suboptimal solutions with respect to the first component (coherence maximization) are overcome.
Additionally, the test with a randomly disturbed initial age-depth function mentioned above indicates that the optimal solution does not strongly depend on the starting point, and the question of local minima therefore was not further investigated.

\section{SUMMARY AND C'ONCLUSIONS}

The mathematical approach suggested by Hasselmann and Herterich [1983] represented an attempt to optimize simultaneously the age-depth function and a linear response model. In this investigation, we have implemented and improved this approach, using a completely different numerical solution strategy. The method presented here provides a universal tool for core calibration and testing of linear relationships between different forcing mechanisms and the response of the climate system on ice age time scales subject to quantified individual preferences. It was possible to improve the SPECMAP calibration in terms of the obtained coherences. The optimal results for the age-depth function of an ocean sediment core are comparable to those given by Herterich and Sarnthein [1984], Imbrie et al. [1984], and Shackleton and Matthews [1977] with energy contained in the spectrum of the correction function itself in a broad band around $100 \mathrm{kyr}$. Therefore the sedimentation rate varies on the same time scale as the ice age cycles. This result has not been observed in earlier investigations, although Martinson et al. [1982] were able to reproduce a sawtooth-shaped function similar to the original $\delta^{18} \mathrm{O}$ data curve for artificial data sets that were passed through a majping function which consisted of a linear trend modified by an oscillatory component with energy in the same frequency as the original sinusoidal data.

The coherences are higher than in the work by Herterich and Sarnthein [1984] and comparable to those obtained by Imbrie et al. [1984]. It was possible to transfer energy in the data spectrum from the $100 \mathrm{kyr}$ band to the Milankovitch frequency bands, especially at $41 \mathrm{kyr}$, where significant energy was not contained previously.

However, a large fraction of the energy contained in the clata spectrum, particularly in the $100 \mathrm{kyr}$ frequency band, cannot be explained by a 
linear model using solar insolation as input. The saw-toothed shape of the data curve mentioned above suggests that in addition to the interpretation derived from observations by Martinson et al. [1982] a nonlinear moclel, such as that proposed by Imbrie and Imbrie [1980], may be required. The tuning of age-deptli functions to a nonlinear model is more complicated than the case considered here, but is in principle amenable to the same techniques.

The main goal of this investigation, however, was to clevelop an automatic time calibration and dynamical model fitting technique which can be applied to many cores. In order to develop a global picture of the structure of the late Pleistocene climate cycles, it will be necessary to optimize simultaneously the age-depth functions for a number of different cores within the context of a global dynamical model, a task which can be addressed only with the aid of a general inversion method.

\section{APPENDIX: DISCRETE OBJECTIVE FUNCTION}

For the numerical optimization, the objective function $F$ in (15) must be discretized. We assume a uniform discretization $t_{i}=-\tau+i \Delta t(i=$ $1, \ldots, M)$ in the time interval $I=[-\tau, 0]$. The continuous correction $x(t)$ is then replaced by a vector $x=\left(x_{1}, \ldots, x_{M}\right)^{T} ; x_{\imath}=x\left(t_{\imath}\right)$. For the formal minimization algorithm, the parameters of the preferred model are added to the independent vector $x$, forming the last two components $x_{M+1}$ and $x_{M+2}$. For a given vector $x:=$ $\left(x_{1}, \ldots, x_{M+2}\right)^{T}$, the frequency response $H_{3}:=$ $H\left(f_{\jmath}\right)$ of the optimally fit linear system is computed from (14) at all $M$ frequencies $f_{3} . H_{3}$ depends not only on frequency but also on the correction and parameter vector $x, H_{\jmath}=: H_{j}(x)$. At all time nodes it is now possible to compute the output of the optimally fitted linear system $y\left(t_{3}\right)$ as the discrete inverse Fourier transform of $Y=H R$. Again, this output depends on the independent vector $x, y_{j}(x):=y\left(t_{j}\right)$. The transfer function of the preferred linear system depends also on $x$

$$
H_{0,3}(x):=H_{0}\left(f_{J}\right),
$$

since the last two components of $x$ are the parameters $\alpha$ and $\lambda$. The discretized objective function is thus given by

$$
\begin{aligned}
& F(x)=g_{1} \sum_{\jmath=1}^{M}\left(y_{\jmath}(x)-y_{d a t}\left(x_{\jmath}+c_{0}\left(t_{\jmath}\right)\right)\right)^{2} \\
& +g_{2} \sum_{\jmath=1}^{M} x_{\jmath}^{2} \\
& +g_{3} \sum_{\jmath=2}^{M-1}\left(\frac{x_{\jmath-1}-2 x_{j}+x_{\jmath+1}}{\Delta t^{2}}\right)^{2} \\
& +g_{4} \sum_{k=1}^{K}\left(c_{k}-\left(c_{0}\left(t_{\jmath(k)}\right)+x_{\jmath(k)}\right)\right)^{2} \\
& +g_{5} \sum_{\jmath=-M / 2+1}^{M / 2}<\left|R\left(f_{\jmath}\right)\right|^{2}>\left|H_{\jmath}(x)-H_{0, \jmath}(x)\right|^{2} \\
& +g_{6} \sum_{\jmath=1}^{M-1} x_{\jmath}^{2}\left(c_{n e w}\left(t_{\jmath+1}\right)-c_{n e w}\left(t_{\jmath}\right)\right)^{2},
\end{aligned}
$$

where

$$
\begin{array}{ll}
\chi_{\jmath}=1 & c_{\text {new }}\left(t_{\jmath+1}\right)-c_{n e w}\left(t_{\jmath}\right) \leq 0 \\
\chi_{\jmath}=0 & \text { otherwise. }
\end{array}
$$

This defines a discrete, nonlinear, least squares optimization problem with an objective function that maps the $M+2$-dimensional Euclidean space to the real line.

The nonlinear dependence of the optimization problem should not be confused with the most probalbly nonlinear relation of solar insolation and global ice volume, although the dynamical models used to describe this relation are linear. The optimization problem is nonlinear, since the first $M$ components of the independent vector $x$ are the individual corrections to the age-depth function, and the input to the objective function is given by the value of the interpolated data function at the corresponding time nodes. One particular problem is that the objective function is not differentiable due to the linear interpolation used in between the points where the data were sampled in the core originally. This problem can be overcome, however, by cubic spline interpolation. Least squares problems with many degrees of freedom are usually poorly conditioned. The discon- 
tinuities of the first derivative further reduce the stability. We therefore applied a rather robust and fast optimization algorithm called PLMA (preconditioned limited memory quasi-Newton algorithm) [cf. Gill and Murray, 1979].

Numerical approximations of the first derivatives were used. Initially, forward differences were used until these approximations failed a simple test (computing directional derivatives either directly or as a scalar product of the gradient and the chosen unit direction). This usually occurs in the vicinity of an optimum, and we then switched to the more time consuming central differences for higher accuracy.

A comprehensive discussion of optimization algorithms as well as the treatment of numerical problems such as stability, convergence of algorithms and preconditioning can be found in the book by Gill et al. [1981]. The numerical difficulties of this particular problem are discussed in detail by Brüggemann [1990].

Acknowledgments. This work was developed from a Diplomarbeit (Master's thesis) at the Institut für Angewandte Mathematik der Universität Hamburg and the Max-Planck-Institut für Meteorologie in Hamburg. In writing my thesis and this article I have received help and advice from many people. In particular, I would like to thank G. Opfer and K. Hasselmann for their support and advice and K. Herterich, B. D. Santer, and T. J. Crowley for helpful discussions. All computations were carried out on the Cray2 of the Deutsches Klimarechenzentrum (DKRZ) in Hamburg. M. Sarnthein provided the data series for the core M 13519, while W. Howard supplied the SPECMAP and ETP clata from J. Imbrie et al. A. Berger provided a computer program to calculate solar insolation in the past. During visits with L. Labeyrie at the Centre des Faibles Radioactivités (CRNS) in Gif sur Yvette, France and with M. Sarnthein at the GeologischesPaläontologisches Institut (CAU) in Kiel I learned the basics about the extraction of the data from deep-sea cores. The Figures were drawn expertly by M. Grunert. Terry Hagelberg. an anonymous reviewer, the editor, and the senior editor supplied valuable suggestions which greatly improved the original manuscript.

\section{REFERENCES}

Berger, A. L., A simple algorithm to compute long term variations of daily or monthly insolation, Contrib.18, 36 pp., Inst. d'Astron. de Louvain, Louvain, Belgium, 1978.

Brüggemann, W., Optimierung der Alterstiefenzuordnung von Tiefseebohrkernen, Diplomarbeit, 122 pp., Univ. of Hamburg, Hamburg, Germany, 1990.

Crowley, T. J., and G. R. North, Paleoclimatology, 339 pp., Oxford University Press, New York, 1991.

Gill, P. E., and W. Murray, Conjugate-gradient methods for large-scale nonlinear optimization, Tech. Rep. SOL $79-15,59$ pp., Syst. Optimization Lab., Dep. of Oper. Res., Stanford Univ., Stanford, Calif., 1979.

Gill, P. E., W. Murray, and M. H. Wright, Practical Optimization, 401 pp., Academic, San Diego, Calif., 1981.

Grieger, B., Orbital tuning of marine sedimentary cores: An automatic procedure based on a general linear model, Rep. 79, 30 pp., MaxPlanck-Inst. für Meteorol., Hamburg, Germany, 1992.

Hasselmann, K., and K. Herterich, Application of inverse modelling techniques to palaeoclimatic data, in Paleoclimatic Research and Models, edited by A. Ghazi, pp. 52 - 68, D. Reidel, Hingham, Mass., 1983.

Hays, J. D., J. Imbrie, and N. J. Shackleton, Variations in the Earth's orbit: Pacemaker of the ice ages, Science. 194, 1121 - 1132, 1976.

Herterich, K., Extracting the parameters of simple climate models by inverse modeling of the deepsea core climatic record, Rep. 2.3, 23 pp., MaxPlanck-Inst. für Meteorol., Hamburg, Germany, 1988 .

Herterich, K., and M. Sarnthein, Brunhes time scale: Tuning by rates of calcium-carbonate dissolution and cross spectral analyses with solar insolation, in Milankovitch and Climate, Part 1, edited by A. L. Berger, J. Imbrie, J. D. Hays, G. Kukla, and B. Saltzman, pp. 447 - 466, D. Reidel, Hingham, Mass., 1984.

Hilgen, F. J., Astronomical calibration of Causs to Matuyama sapropels in the Mediterranean and 
implication for the geomagnetic polarity time scale, Earth Planet. Sci. Lett., 10/, $226-244$, 1991.

Imbrie, J., and J. Z. Imbrie, Modeling the climatic response to orbital variations, Science, 207, 943 - 953, 1980.

Imbrie, J., J. D. Hays, D. G. Martinson, A. McIntyre, A. C. Mix, J. J. Morley, N. G. Pisias, W. L. Prell, and N. J. Shackleton, The orbital theory of Pleistocene climate: Support from a revised chronology of the marine $\delta^{18} \mathrm{O}$ record, in $\mathrm{Mi}$ lankovitch and Climate, Part 1, edited by A. L. Berger, J. Imbrie, J. D. Hays, G. Kukla, and B. Saltzman, pp. 269 - 305, D. Reidel, Hingham, Mass., 1984.

Imbrie, J., A. McIntyre, and A. Mix, Oceanic response to orbital forcing in the late quaternary: Observational and experimental strategies, in Climate and Geo-Sciences, edited by J.-C. Duplessy, A. Berger, and S. H. Schneider, pp. 121 164, D. Reidel, Hingham, Mass., 1989.

Izett, G. A., and J. D. Obradovich, Dating of the Matuyama-Brunhes Boundary Based on ${ }^{40} \mathrm{Ar} /{ }^{39} \mathrm{Ar}$ Ages of the Bishop Tuff and Cerro San Luis Rhyolite, Annual Meeting, Geol. Soc. of Am., San Diego, Oct. 21-24, 1991.

Jenkins, G.M., and D.G. Watts, Spectral Analysis and Its Applications, 525 pp., Holden-Day, Oakland, Calif., 1968.

Kirkpatrick, S., C. D. Gelatt, Jr., and M. P. Vecchi, Optimization by simulated annealing, Science, 220, 671 - 680, 1989.

Martinson, D. G., W. Menke, and P. Stoffa, An inverse approach to signal correlation, J. Geophys. Res.. 87, 4807 - 4818, 1982.

Martinson, D. G., N. G. Pisias, J. D. Hays, J. Imbrie, T. C. Moore, and N. J. Shackleton, Age dating and the orbital theory of the ice ages: Development of a high-resolution 0 to 300 000year chronostratigraphy, Quart. Res., 27, 1 29, 1987.

Metropolis, N., A. W. Rosenbluth, M. N. Rosenbluth, A. H. Teller, and E. Teller, Equation of state calculations by fast computing machines, J. Chem. Phys., 21, 1087 - 1092, 1953.
Milankovitch, M., Astronomische Mittel zur Erforschung der erdgeschichtlichen Klimate, in Handbuch der Geophysik IX, Band 3, edited by B. Gutenberg, pp. 593 - 698, Verlag Gebrüder Borntraeger, Berlin, 1938.

Prell, W. L., J. Imbrie, D. G. Martinson, J. J. Morley, N. G. Pisias, N. J. Shackleton, and H. F. Streeter, Graphic correlation of oxygen isotope stratigraphy application to the Late Quaternary, Paleoceanography, 1, $137-162,1986$.

Sarnthein, M., H. Erlenkeuser, R. von Grafenstein, and C. Schröder, Stable-isotope stratigraphy for the last 750000 years: "Meteor" core 13519 from the eastern equatorial Atlantic, "Metcor" Forschungsergeb., Reihe C, 38, 9 - 24, 1984.

Shackleton, N. J., and R. K. Matthews, Oxygen isotope stratigraphy of Late Pleistocene coral terraces in Barbados, Nature, 268, 618 - 620, 1977.

Shackleton, N. J., and N. D. Opdyke, Oxygen isotope and paleomagnetic stratigraphy of Equatorial Pacific Core V28-238: Oxygen isotope temperatures and ice volumes on a $10^{5}$ year and $10^{6}$ year scale, Quart. Res., 3, 39 - 55, 1973.

Shackleton, N. J., A. Berger, and W. R. Peltier, An alternative astronomical calibration of the lower Pleistocene timescale based on ODP Site 677, Trans. R. Soc. Edinburgh Earth Sci., 81, $251-261,1990$.

Walter, R. C., P. C. Manega, R. L. Hay, R. E. Drake, and G. H. Curtis, Laser-fusion ${ }^{40} \mathrm{Ar} /{ }^{39} \mathrm{Ar}$ dating of Bed I, Olduvai Gorge, Tanzania, $\mathrm{Na}$ ture. 354, 145 - 149, 1991.

W. Brüggemann, Max-Planck-Institut für Meteorologie Hamburg, Bundestraße 55, 2000 Hamburg 13, Germany.

(Received January 11, 1992;

revised May 27, 1992;

accepted May 28, 1992.) 